\title{
Effects of Different Relative Humidities on Flax Fibers prior to Manufacturing Their Composites Based on the Shear Response
}

\author{
Abdul Moudood (D), ${ }^{1}$ Anisur Rahman, ${ }^{1}$ Andreas Öchsner, ${ }^{2}$ Md Mainul Islam (D), ${ }^{3}$ \\ Mohammad Yeakub Ali, ${ }^{4}$ and Gaston Francucci ${ }^{5}$ \\ ${ }^{1}$ Griffith School of Engineering and Built Environment, Gold Coast Campus, Griffith University, Southport, \\ Queensland 4222, Australia \\ ${ }^{2}$ Esslingen University of Applied Sciences, Faculty of Mechanical Engineering, Kanalstrasse 33, 73728, Esslingen, Germany \\ ${ }^{3}$ School of Mechanical \& Electrical Engineering, University of Southern Queensland, West Street, Toowoomba, \\ QLD 4350, Australia \\ ${ }^{4}$ Mechanical Engineering Programme Area, Faculty of Engineering, Universiti Teknologi Brunei, Tungku Highway, Gadong, \\ Bandar Seri Begawan BE1410, Brunei Darussalam \\ ${ }^{5}$ Research Institute of Material Science and Technology (INTEMA-CONICET), National University of Mar del Plata, \\ J. B. Justo 4302, B7608FDQ, Mar del Plata, Argentina
}

Correspondence should be addressed to Md Mainul Islam; mainul.islam@usq.edu.au

Received 31 May 2020; Accepted 20 July 2020; Published 3 August 2020

Academic Editor: Veronica Calado

Copyright ( $) 2020$ Abdul Moudood et al. This is an open access article distributed under the Creative Commons Attribution License, which permits unrestricted use, distribution, and reproduction in any medium, provided the original work is properly cited.

\begin{abstract}
The moisture absorption behavior of flax fiber-reinforced epoxy composites is deliberated to be a serious issue. This property restricts their usage as outdoor engineering structures. Therefore, this study provides an investigation of moisture in flax fibers on the performance of the flax/epoxy composite materials based on their shear responses. The $\pm 45^{\circ}$ aligned flax fibers exposed to different relative humidities $(\mathrm{RH})$ and the vacuum infusion process was used to manufacture the composite specimens. The optimum shear strength $(40.25 \pm 0.75 \mathrm{MPa})$ was found for the composites manufactured with $35 \% \mathrm{RH}$-conditioned flax fibers, but the shear modulus was reduced consistently with increasing RH values. Although shear strength was increased because of fiber swelling with increased moisture absorption rate until 35\% RH environments with good microstructures, nonetheless, strength and modulus both started to decrease after this range. A very poor microstructure has been affirmed by the SEM images of the composite samples conditioned at $90 \% \mathrm{RH}$ environments.
\end{abstract}

\section{Introduction}

In the recent years, a huge utilization of natural fibers extracted and processed from plants can be seen in fiberreinforced composites (FRC) as a filler or in the form of reinforcement. This trend is increasing every year based on their environmental and economic perspective. Researchers all over the world are increasingly interested in these materials as they are sustainable and recyclable during their usage in many engineering applications. There is a long history of using synthetic fiber composites for various purposes ranging from household to aerospace industries.
However, the growing environmental concern about global warming and increasing rate of greenhouse gases forced the researchers to consider other possible alternatives. Plant fiber-reinforced composite materials are one of those alternatives which are consequently replacing synthetic fiber composites.

The predominant synthetic fibers such as glass and carbon fibers and their composites are generally termed as high-performance composites. These composites generate solid waste because of their recyclability problem which has a correlation to many environmental issues [1]. In contrast, natural plant fiber composites are increasingly used in 
engineering structures as natural fibers, and their composites possess lower weight and density, cost benefits, being renewable in nature, and many of their mechanical properties are comparable to those of synthetic fiber composites [2]. Furthermore, natural fibers are easily available, nonabrasive, and nontoxic, and their extraction and production processes are almost free from environment pollution. Natural plant fiber composites, therefore, generate very low tool wear rate and require a very small amount of fossil fuels during their production, and they also have good thermal and acoustic insulation properties. These fibers have the potential to substitute the conventional synthetic fiber reinforcements for those applications which require high strength-to-weight ratio and even further reduction of weight [3]. Despite the wide range of benefits, plant fiber composites have a few drawbacks too. The main constituents of plant fibers are lignocelluloses (cellulose, hemicellulose, lignin, and pectin). Plant fiber-reinforced composites have a tendency to absorb moisture under different environmental conditions such as relative humidity $(\mathrm{RH})$, temperature, and so on. Araújo et al. [4] stated that most plant fiber composites start degrading after $200^{\circ} \mathrm{C}$. On the other hand, these composites showed complex behavior when they absorb moisture. Fibers might swell at the fiber-matrix interfaces of the composites when they absorb moisture content. As a result, cracks, microcracks, pores, or voids generate at the interfaces to deteriorate the composite quality because of the reduction of dimensional stability and/or mechanical properties.

Flax is an important vegetal fiber. In Europe, this fiber has a significant market for reinforcement in FRC for the linen sector. The specific properties of flax fiber composites are within the global trend towards a sustainable development when economic and ecological benefits are both considered [5]. Numerous applications of flax composites for different purposes made this material increasingly demandable to the researchers. Flax fiber-reinforced composites have the potential for widespread utilization in sports industries (bike frames, stand-up paddles, and many types of boards), automotive accessories (dashboards and door panels), and maritime industry (small-to-medium boats). Nonetheless, heavy-duty flax prepregs $\left(300\right.$ to $550 \mathrm{gm} / \mathrm{m}^{2}$ ) are being produced for future usage in the aeronautical industry [6].

The mechanical properties of flax composites over their moisture absorption behavior have been investigated in many studies [7-12]. For example, Moudood et al. [13] studied the tensile and flexural behaviors of the flax composite manufactured with fibers exposed to different $\mathrm{RH}$ values. They found that flax fibers absorb moisture steadily until $70 \% \mathrm{RH}$. However, this absorption rate was double from the $70 \% \mathrm{RH}$ to $95 \% \mathrm{RH}$ value. The tensile strength of the composite specimens was increased up to $50 \% \mathrm{RH}$. In fact, optimum strength $(23 \mathrm{MPa})$ was found at $50 \% \mathrm{RH}$. After this $\mathrm{RH}$, strength was reduced until a maximum $\mathrm{RH}$ value $(95 \% \mathrm{RH})$, but the tensile modulus was decreased continuously with increasing RH. They reported that plasticization of the water molecules within the flax fibers was responsible for increasing the fracture strain and continuous decrease of Young's modulus. In addition, they confirmed a weak fiber/matrix interface and a significant number of voids and microcracks in their microstructure after the composites were manufactured with fibers at $50 \% \mathrm{RH}$ environments. However, flexural strength and modulus were reduced continuously with increasing moisture content from lower to higher RH values. In a different work [14], they further studied the properties of flax/bioepoxy composites under several different environmental conditions: water immersion, warm humid environment, and freezethaw conditions. The composites manufactured with these conditions were also compared with the "as-manufactured (AM)" composite samples. The AM samples were best performed in case of tensile and flexural properties. Flax composites suffered mostly during their water immersion tests as these samples lost 9\% strength and 57\% modulus when they were compared with the AM samples. However, these changes were only $0.8 \%$ and $3 \%$, respectively, for the samples exposed to $75 \% \mathrm{RH}$ and $45^{\circ} \mathrm{C}$. On the other hand, water-immersed composite samples lost the flexural strength and modulus by $64 \%$ and $70 \%$, respectively, when they were compared with the AM samples. In both cases (tensile and flexural behavior), freezing-thawing cycles have almost no effects on the composite samples. Sawi et al. [15] also investigated the mechanical properties of flax/epoxy composites under different manufacturing conditions and curing temperatures. They reported the tensile, flexural, and shear properties and the effects of water absorption on these mechanical properties. The shear response was the most affected property by the manufacturing process among the three different properties as the shear modulus was reduced by $60 \%$ due to the water absorption behavior. No significant changes were evident for the tensile modulus when flax composites were manufactured by two different methods: compression molding and the autoclave process. However, higher tensile strength $(307 \mathrm{MPa})$ was found when they were cured at $150^{\circ} \mathrm{C}$, rather than cured at $110^{\circ} \mathrm{C}$. The authors further reported that water absorption behavior also reduced their flexural modulus from $25 \mathrm{GPa}$ to $11 \mathrm{GPa}$, but no changes were observed for the flexural strength.

In contrast to the studies discussed above which focused on the effects of different environmental conditions on the tensile, flexural, and other mechanical properties of flax composites, the effects of different $\mathrm{RH}$ values on the shear responses of flax composites still need more attention. The present study focuses on the effects of different $\mathrm{RH}$ values on the flax fibers prior to manufacturing their composites. These effects were investigated by measuring the shear strength and modulus of the flax/epoxy composites manufactured with the fibers exposed to different $\mathrm{RH}$ values. In addition, scanning electron microscopy (SEM) observations were conducted to analyze the microstructures of the differently humidified composite samples.

\section{Experimental Details}

2.1. Materials. The commercially available FlaxPLY UD 180 (fabric pretreated with 16\% epoxy-based resin), supplied by Lineo (France), has been used. The areal weight of the fabric was $180 \mathrm{gm} / \mathrm{m}^{2}$ according to the material safety data sheet. 

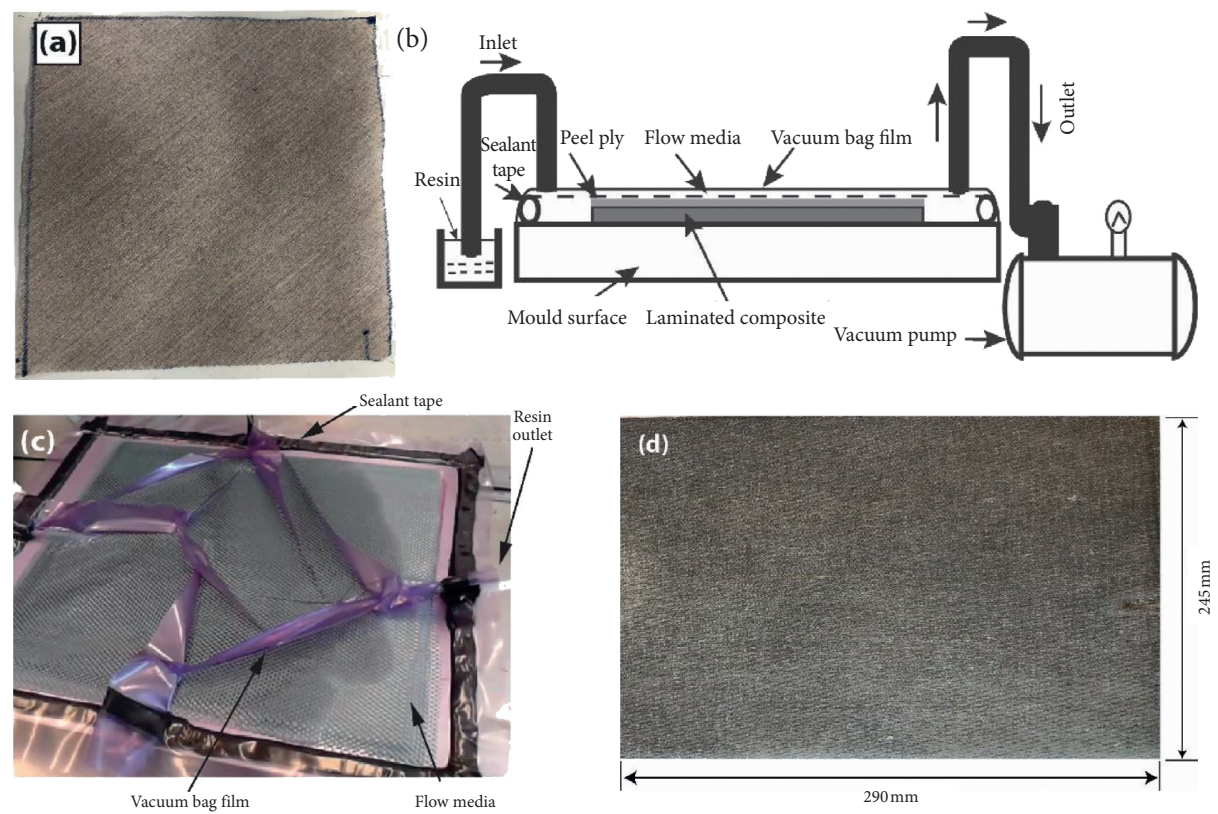

Figure 1: Composite plates manufacturing process: (a) surface image of the flax fabric, (b) schematic of the vacuum infusion process, (c) setup of the vacuum infusion process: ongoing resin infusion, and (d) composite plate.

The epoxy system, resin and hardener, was from Nuplex Industries (Aust) Pvt Ltd. with an epoxy-hardener ratio of 5 : 1 by weight and was used as per specification.

\subsection{Composite Manufacturing. The flax fiber-reinforced} epoxy composite plates $(245 \mathrm{~mm} \times 290 \mathrm{~mm})$ were manufactured by the vacuum infusion technique using flax fiber fabrics that had been exposed to different levels of relative humidity $(\mathrm{RH})$ in a climate chamber $(\mathrm{CH} 700 \mathrm{~V}$, Angelantoni): $35 \%, 50 \%, 70 \%$, and $90 \% \mathrm{RH}$. A dehydrating oven (TD300F, Thermoline Scientific) was used to dry the fabrics at $60^{\circ} \mathrm{C}$ for $4 \mathrm{~h}$ before manufacturing the "dry" composite samples. The shear test ASTM standard [16] requires a preform having a fabric stacking sequence of $( \pm 45)_{\text {ns }}$ with $2<n<4$. Hence, 8 layers of reinforcement were used to avoid the tension-flexion coupling during manufacturing of the epoxy-flax laminate plates (Figure 1). The fiber volume factions of the laminates are listed in Table 1.

The details of the manufacturing process of the composite plates with the curing cycle temperature and pressure, humidification, and drying process of the flax fibers are reported in [13].

\subsection{Mechanical Testing}

2.3.1. In-Plane Shear Testing. A laser cutter (model: TROTEC Speedy 300) was used to cut the test specimens (size: $250 \times 25 \times 2.5 \mathrm{~mm}$ ) from the composite plates. In order to specify the effects of $\mathrm{RH}$ on the in-plane shear properties of the flax composites, the test specimens were prepared according to the ASTM D 3518/D 3518M-94 [16]. The inplane shear properties were measured from tensile tests on specimens with $\pm 45^{\circ}$ aligned flax fibers with regard to the loading direction. All tests were carried out with an Instron
TABle 1: Average fiber volume fraction of the specimens under different relative humidities.

\begin{tabular}{lc}
\hline$\%$ Relative humidity $(\mathrm{RH})$ & Fibre volume fraction $(\%)$ \\
\hline 0 & 38.1 \\
35 & 30.5 \\
50 & 33.3 \\
70 & 34.8 \\
90 & 35.1 \\
\hline
\end{tabular}

3367 universal testing machine (serial no. 68296) using a $30 \mathrm{kN}$ load cell and a test speed rate of $2 \mathrm{~mm} / \mathrm{min}$. The longitudinal and transverse strains were measured by using a biaxial static type extensometer (serial no. 673, travel limit: $+25 /-2.5 \mathrm{~mm}$ ). The evaluation of the experiments delivered the shear stress $\left(\tau_{x y}\right)$, shear strain $\left(\gamma_{x y}\right)$, and the shear modulus $\left(G_{x y}\right)$. The shear stress was the maximum stress upon the specimen failure, and the modulus was obtained from the slope of the plot of shear stress versus shear strain in the shear strain range between $0 \%$ and $2 \%$ (the linear part of the graph). The experimental setup for in-plane shear stress and shear test specimens are illustrated in Figure 2. For all the shear strength, modulus, and strain value calculation, at least 5 specimens were tested, and their average values were taken for each environmental condition. The shear stress was calculated by using the following equation:

$$
\tau_{x y}=\frac{\sigma_{x}}{2}
$$

where $\sigma_{x}$ is the applied normal stress.

2.3.2. Scanning Electron Microscopy (SEM). Specimen surfaces of the flax composites were polished with sandpaper (P2500 grain size) and coated with a thin layer of platinum 

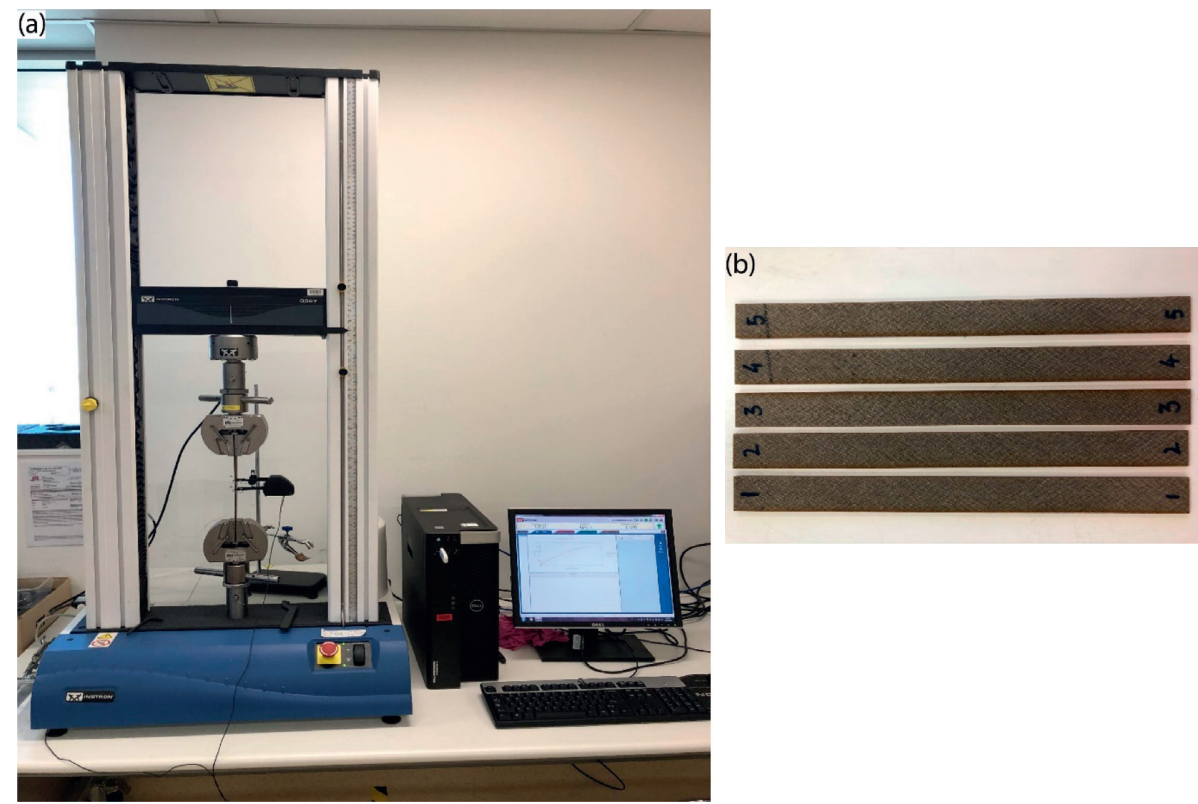

Figure 2: Experimental setup (a) and in-plane shear specimens (b).

before microstructural analysis. After that, the specimen surfaces were analyzed by using a SEM (model: Jeol FESEM JSM-7100F).

\section{Results and Discussion}

3.1. In-Plane Shear Response. The in-plane shear properties of the flax/epoxy composite samples are illustrated in Figures 3 and 4 . The shear strengths were increased from dry to $35 \%$ RH-conditioned fiber-reinforced composite samples. Strength started to reduce with increasing RH values after this value (35\% RH). In a previous study [13], the authors showed that moisture absorption rates of flax fibers increase with the increasing $\mathrm{RH}$ values. After $35 \% \mathrm{RH}$, a steady reduction in strength was evident; therefore, the optimum shear strength was found at 35\% RH. The shear strength was increased from dry samples $(31.07 \mathrm{MPa})$ to the samples conditioned at $35 \% \mathrm{RH}$ environments $(40.25 \mathrm{MPa})$. After this range, however, a continuous reduction of strength was observed for 50\% RH (38.9736 MPa), 70\% RH (36 MPa), and $90 \% \mathrm{RH}(34.72 \mathrm{MPa})$ environments. On the other hand, the shear modulus decreased for the composite samples from $0 \%$ $\mathrm{RH}$ to $90 \% \mathrm{RH}$. The highest shear modulus (3.16 GPa) was obtained for the composites manufactured with dry fiber fabrics, although nearly the same modulus ( $3.12 \mathrm{GPa}$ ) can be obtained with $35 \% \mathrm{RH}$ value. It was found that a much less shear modulus $(2.64 \mathrm{GPa})$ can be obtained for the composites manufactured with fibers exposed to $90 \% \mathrm{RH}$ environments.

Higher shear strength of the humidified samples than the dry fiber composite samples might be attributed to the fiber swelling when exposing to high moisture at a high RH value. The fiber swelling can fill the gaps between the fiber and the resin material during the vacuum infusion process as poor impregnation of resin shrinkage might occur during the curing process. This can increase the mechanical properties

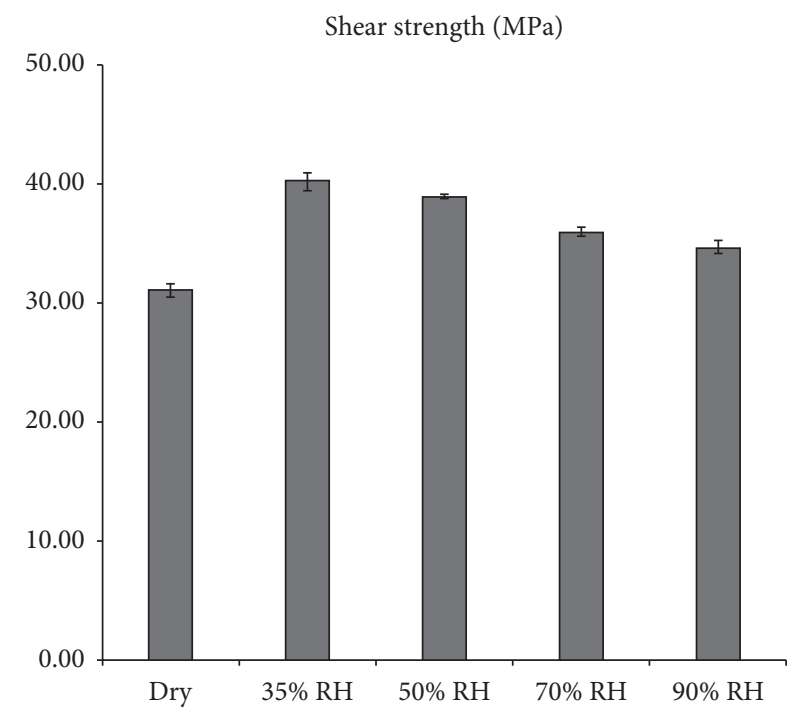

FIGURE 3: Shear strength of the flax/epoxy composite samples.

of the plant fiber composites. A number of studies $[13,17-19]$ have reported this phenomenon for the tensile properties of the plant fiber composites. However, Karmaker et al. [20] reported that higher shear strength can be obtained during fractured stages when swelled fibers fill the gaps between the fiber-matrix interfaces. Sawi et al. [15] stated that shear properties of the flax composites are controlled by the fiber-matrix interface and by the matrix material. Cellulose is the dominant constituent of the flax fibers which contains hydroxyl (-OH) groups. At higher $\mathrm{RH}$ values, fibers start to absorb more moisture contents. Therefore, the hydrogen bonds between the hydroxyl (-OH) groups of the cellulose and the epoxy matrix might be destroyed, and consequently, poor dimensional stability and interfacial bonds could be the end results. Therefore, shear 


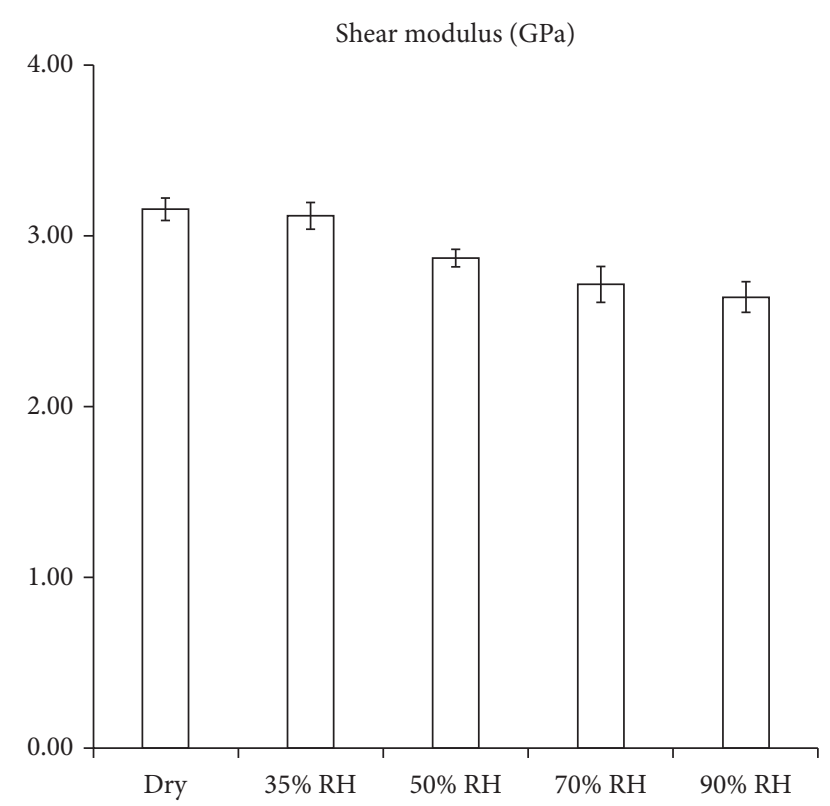

Figure 4: Shear modulus of the flax/epoxy composite samples.

strengths started to decrease after 35\% RH environments. After this range (i.e., 35\% RH), the strength values were started to decrease until the maximum humidity level $(90 \%$ $\mathrm{RH})$. Although moisturized composite samples under higher $\mathrm{RH}$ values possess greater strengths than the dry $(0 \% \mathrm{RH})$ ones, their microstructural analysis confirmed that the debonding between the fiber and the matrix and other microdefects were evident which has been depicted in the SEM analysis. These results were also confirmed by Dhakal et al. [19], referencing to the fact that water molecules destroyed the cellulose network structure by acting as a plasticizer and destroy the rigidity of the cellulose ingredient of the flax fibers.

Figure 5 illustrates the fracture behavior of the flax/ epoxy composite samples during tensile tests under three different environmental conditions. The specimens manufactured with dry and 35\% RH-conditioned flax fibers demonstrated ductile failure. The angular plies started to reorient along the axis of the load after the point of inflection. Therefore, the fiber angle was stepped down from $45^{\circ}$ before fracture and delamination occurred. However, brittle failure was found for the composite samples manufactured with $90 \% \mathrm{RH}$ conditioned flax fibers. This failure was governed by the fiber pull out and debonding of fibers from the matrix.

Figure 6 shows the typical shear stress-strain curves for all the composite samples. First, a linear region is observed, and then, the slope of the curves is nonlinear until failure. Liang et al. [21] reported that the matrix material was responsible for this behavior during assessing the damage of flax/epoxy composite material. From Figure 6, it is clear that the highest shear properties can be obtained by using $35 \% \mathrm{RH}$ environments. The existence of free water molecules, which are generated by the cellulose fibril of the flax fibers and the matrix material due to the presence of $-\mathrm{OH}$ groups weaken the strength of the interface. As a result,

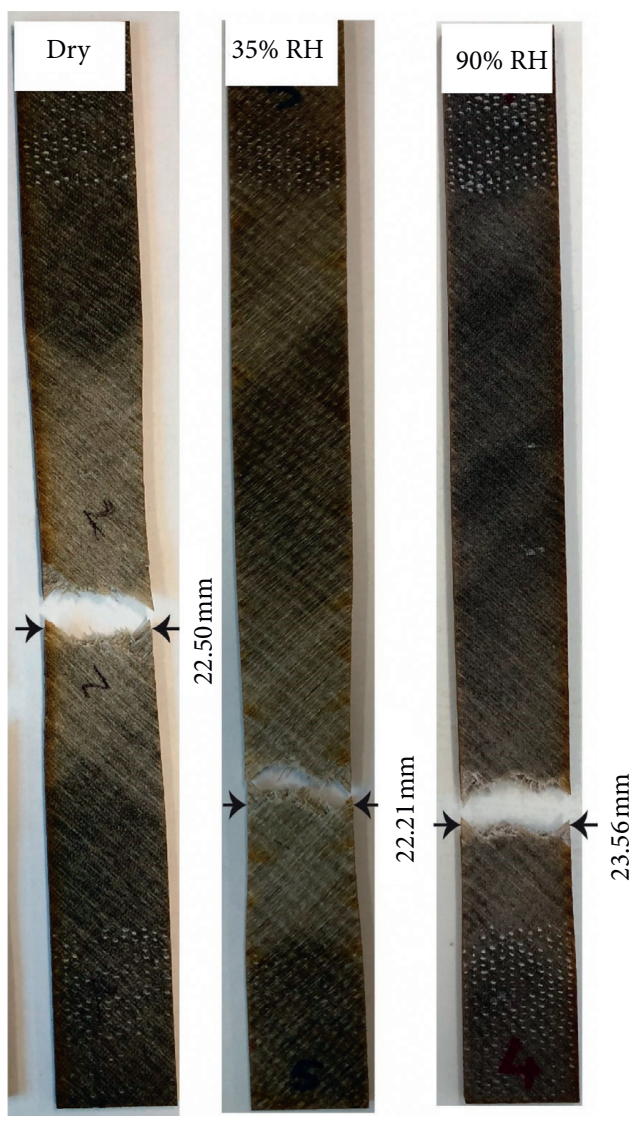

FIgURE 5: In-plane shear failure during tensile tests of $\pm 45^{\circ}$ aligned flax/epoxy composite samples.

debonding might occur to accelerate the damage, and microcracks and pores could be initiated to the fiber/matrix interface.

3.2. SEM Analysis. Figures 7(a)-7(c) demonstrate the SEM microstructures of the composite samples. These images are the cross-sectional cut of the specimens. The composites manufactured with dry fiber fabrics $(0 \% \mathrm{RH})$ showed microcracks, crack growth around the fiber bundles, and interfacial cracks into their microstructures (Figure 7(a)) during the shear tests. A healthy microstructure was found for the composites manufactured with 35\% RH environments (Figure 7(b)). Evidently, a few microcracks were identified in the images. However, the samples manufactured with fibers exposed to $90 \% \mathrm{RH}$ provided poor microstructural quality. In their microstructures, the fiber pull out, matrix cracking, poor interfacial adhesion between the fiber-matrix interfaces, and voids are observed. As explained, the matrix cracking might occur due to fibermatrix debonding and due to the generated residual stresses during the curing stage. On the other hand, $45^{\circ}$ fiber orientation generated more resin-rich areas into the composite samples as compared to the same of the unidirectional one. Therefore, fiber pullout, voids, or microcracks can be contributed into the microstructures, while the fibers are humidified with higher humidity ( $90 \% \mathrm{RH})$ and high moisture 


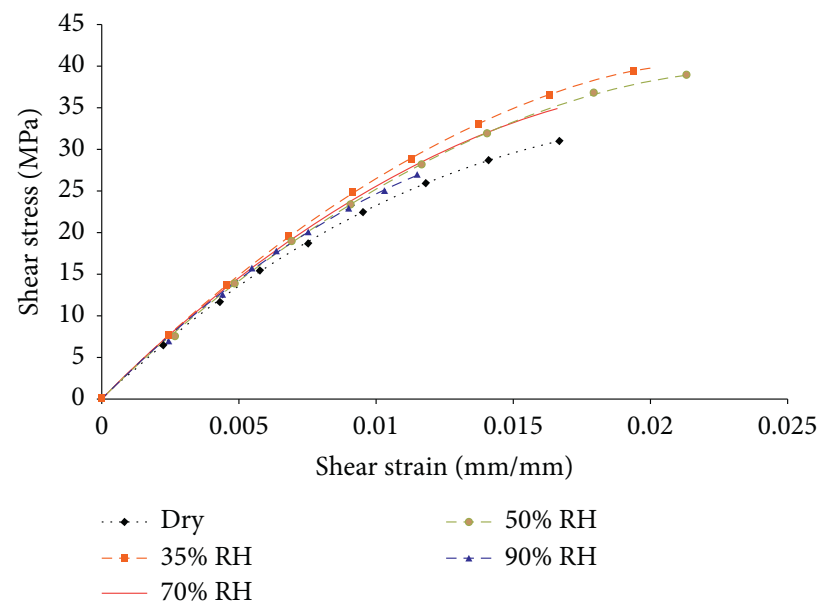

FIGURE 6: Shear stress-strain behavior of the flax/epoxy composite samples under different relative humidities (RH).

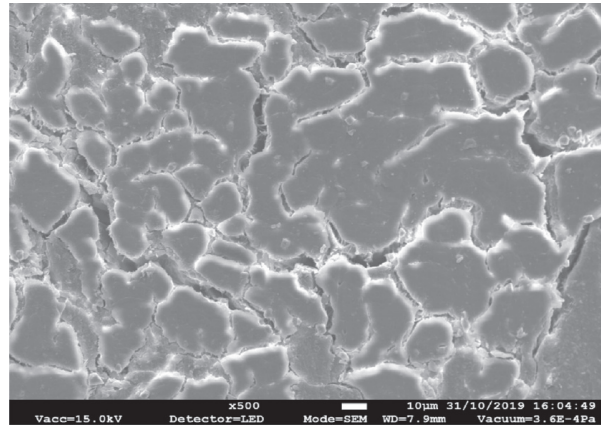

(a)

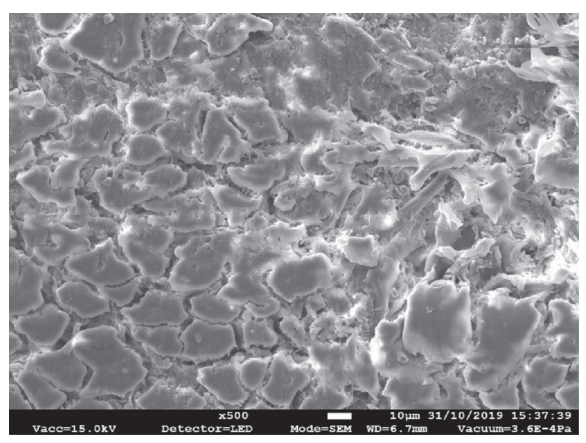

(b)

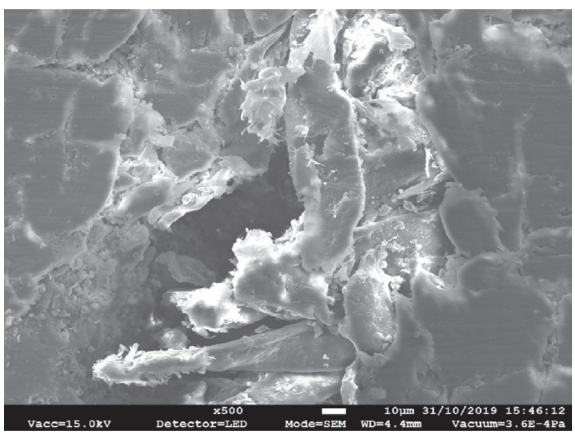

(c)

FIGURE 7: SEM micrographs of the cross sections of the flax/epoxy composite samples: (a) 0\% RH, (b) 35\% RH, and (c) $90 \%$ RH.

absorption rate. This also specified that the epoxy resin could not penetrate completely among the flax fibers.

\section{Conclusions}

This study has represented the effects of different relative humidities $(\mathrm{RH})$ on the flax fibers prior to manufacturing their composites. The performance of the flax/epoxy composites under different $\mathrm{RH}$ environments were evaluated and analyzed by the shear responses. The flax fibers' moisture absorption rate under different $\mathrm{RH}$ values has both positive and negative effects. Optimum shear strength was found in
$35 \% \mathrm{RH}$ environments, which means that the strength increased positively until this value. However, the reduction of strength was observed after this range. Furthermore, shear modulus was reduced with increasing $\mathrm{RH}$ environments. The best microstructures were found for the dry and 35\% $\mathrm{RH}$-conditioned fiber composites, but the worst microstructure for the same confirmed the negative effects of moisture absorption at $90 \% \mathrm{RH}$ environments.

\section{Data Availability}

Data can be made available if needed. 


\section{Conflicts of Interest}

The authors declare that there are no conflicts of interest regarding the publication of this paper.

\section{Acknowledgments}

The financial support from the Publication Assistance Scholarship Scheme (PAS) of Griffith University, Australia, is gratefully acknowledged.

\section{References}

[1] J. A. M. Haameem, M. S. A. Majid, M. Afendi et al., "Effects of water absorption on Napier grass fibre/polyester composites," Composite Structures, vol. 144, pp. 138-146, 2016.

[2] A. Moudood, A. Rahman, A. Öchsner, M. Islam, and G. Francucci, "Flax fiber and its composites: an overview of water and moisture absorption impact on their performance," Journal of Reinforced Plastics and Composites, vol. 38, no. 7, pp. 323-339, 2019.

[3] B. Madsen and E. K. Gamstedt, "Wood versus plant fibers: similarities and differences in composite applications," Advances in Materials Science and Engineering, vol. 2013, Article ID 564346, 14 pages, 2013.

[4] J. R. Araújo, W. R. Waldman, and M. A. De Paoli, “Thermal properties of high density polyethylene composites with natural fibres: coupling agent effect," Polymer Degradation and Stability, vol. 93, no. 10, pp. 1770-1775, 2008.

[5] C. Poilâne, Z. E. Cherif, F. Richard, A. Vivet, B. Ben Doudou, and J. Chen, "Polymer reinforced by flax fibres as a viscoelastoplastic material," Composite Structures, vol. 112, pp. 100-112, 2014.

[6] B. C. Suddell and W. J. Evans, "Natural fiber composites in automotive applications," in Natural Fibers, Biopolymers, and Biocomposites, A. K. Mohanty, M. Misra, and L. T. Drzal, Eds., CRC Press, Boca Raton, Fl, USA, 2005.

[7] M. Assarar, D. Scida, A. El Mahi, C. Poilâne, and R. Ayad, "Influence of water ageing on mechanical properties and damage events of two reinforced composite materials: flaxfibres and glass-fibres," Materials \& Design, vol. 32, no. 2, pp. 788-795, 2011.

[8] S. Alix, E. Philippe, A. Bessadok, L. Lebrun, C. Morvan, and S. Marais, "Effect of chemical treatments on water sorption and mechanical properties of flax fibres," Bioresource Technology, vol. 100, no. 20, pp. 4742-4749, 2009.

[9] K. Cheour, M. Assarar, D. Scida, R. Ayad, and X.-L. Gong, "Effect of water ageing on the mechanical and damping properties of flax-fibre reinforced composite materials," Composite Structures, vol. 152, pp. 259-266, 2016.

[10] A. Chilali, W. Zouari, M. Assarar, H. Kebir, and R. Ayad, "Effect of water ageing on the load-unload cyclic behaviour of flax fibre-reinforced thermoplastic and thermosetting composites," Composite Structures, vol. 183, pp. 309-319, 2018.

[11] A. Chilali, M. Assarar, W. Zouari, H. Kebir, and R. Ayad, "Effect of geometric dimensions and fibre orientation on 3D moisture diffusion in flax fibre reinforced thermoplastic and thermosetting composites," Composites Part A: Applied Science and Manufacturing, vol. 95, pp. 75-86, 2017.

[12] A. Duigou, J. Merotte, A. Bourmaud, P. Davies, K. Belhouli, and C. Baley, "Hygroscopic expansion: a key point to describe natural fibre/polymer matrix interface bond strength," Composites Science and Technology, vol. 151, pp. 228-233, 2017.
[13] A. Moudood, W. Hall, A. Öchsner, H. Li, A. Rahman, and G. Francucci, "Effect of moisture in flax fibres on the quality of their composites," Journal of Natural Fibers, vol. 16, no. 2, pp. 209-224, 2019.

[14] A. Moudood, A. Rahman, H. M. Khanlou, W. Hall, A. Öchsner, and G. Francucci, "Environmental effects on the durability and the mechanical performance of flax fiber/bioepoxy composites," Composites Part B: Engineering, vol. 171, pp. 284-293, 2019.

[15] I. E. Sawi, H. Bougherara, R. Zitoune, and Z. Fawaz, "Influence of the manufacturing process on the mechanical properties of flax/epoxy composites," Journal of Biobased Materials and Bioenergy, vol. 8, no. 1, pp. 69-76, 2014.

[16] ASTM-D 3518/D 3518M-94, "In-plane shear response of polymer matrix composite materials by tensile test of a $\pm 45^{\circ}$ laminate," Annual Book of ASTM Standards, ASTM International, West Conshohocken, PA, USA, 2001.

[17] E. Muñoz and J. A. Garcia-Manrique, "Water absorption behaviour and its effect on the mechanical properties of flax fibre reinforced bioepoxy composites," International Journal of Polymer Science, vol. 2015, Article ID 390275, 10 pages, 2015.

[18] A. Stamboulis, C. A. Baillie, S. K. Garkhail, H. G. H. van Melick, and T. Peijs, "Environmental durability of flax fibres and their composites based on polypropylene matrix," Applied Composite Materials, vol. 7, no. 5-6, pp. 273-294, 2000.

[19] H. N. Dhakal, Z. Y. Zhang, and M. O. W. Richardson, "Effect of water absorption on the mechanical properties of hemp fibre reinforced unsaturated polyester composites," Composites Science and Technology, vol. 67, no. 7-8, pp. 1674-1683, 2007.

[20] A. C. Karmaker, A. Hoffmann, and G. Hinrichsen, "Influence of water uptake on the mechanical properties of jute fiberreinforced polypropylene," Journal of Applied Polymer Science, vol. 54, no. 12, pp. 1803-1807, 1994.

[21] S. Liang, P.-B. Gning, and L. Guillaumat, "Quasi-static behaviour and damage assessment of flax/epoxy composites," Materials \& Design, vol. 67, pp. 344-353, 2015. 